\title{
Microwave heating: a promising and eco-compatible solution to fight the spread of red palm weevil
}

\author{
R. Massa' ${ }^{1}$, G. Panariello², M.D. Migliore ${ }^{2}$, D. Pinchera ${ }^{2}$, F. Schettino ${ }^{2}$, R. Griffo ${ }^{3}$, \\ M. Martano ${ }^{4}$, K. Power ${ }^{4}$, P. Maiolino ${ }^{4}$ and E. Caprio ${ }^{5}$
}

(1) Department of Physics "Ettore Pancini", University of Naples Federico II, Via Cintia - Complesso Monte S. Angelo, 80126, Naples, Italy, email: massa@ unina.it; (2) Department of Electrical and Information Engineering "Maurizio Scarano", University of Cassino and Southern Lazio, Cassino, Via G. Di Biasio, 43 - 03043 - Cassino (FR), Italy; (3) Plant Protection Service of Campania Region, Centro Direzionale, Isola A6 - 80143, Naples, Italy; (4) Department of Veterinary Medicine and Animal Production, University of Naples Federico II; Via Delpino 1, 80137, Naples, Italy; (5) Department of Agricultural Sciences, University of Naples Federico II, Reggia di Portici - Via Università, 100 - 80055 - Portici Naples, Italy.

\section{Abstract}

Massa, R., G. Panariello, M.D. Migliore, D. Pinchera, F. Schettino, R. Griffo, M. Martano, K. Power, P. Maiolino and E. Caprio. 2019. Microwave heating: a promising and eco-compatible solution to fight the spread of red palm weevil. Arab Journal of Plant Protection, 37(2): 143-148.

The red palm weevil is one of the major pests of palms. Until now no effective and economic method has been adopted for the total eradication of this pest and some concerns are raised for chemical methods, mainly in ornamental plants located in urban areas. Among the proposed techniques, a very promising and eco-compatible solution is the palm microwave heating, which could be integrated in a IPM approach. Advantages of microwave disinfestation include speed, efficiency and the absence of toxic, hazardous or polluting residues. Moreover, insects are not likely to develop a resistance to radiation as they often do to chemical insecticides. This work aims to resume our results on the feasibility of microwave applications on infested Phoenix canariensis palms. Temperatures that can be lethal to insects applied on the external layers do not affect the internal palm tissues. Moreover, microwaves can influence the ability of reproduction of the survived weevils. Once the physical/thermal parameters of the tissues were determined, a protocol of duration of time and schedule (on-off cycles) was developed for a better control of the temperature profile inside the palm. In this way, the lethal temperature dose for the insects was applied using a ring microwave applicator.

Keywords: non ionizing radiation, pest control, alien invasive pest.
\end{abstract}

\section{Introduction}

The invasive Red Palm Weevil (RPW), Rhynchophorus ferrugineus Olivier (Coleoptera, Curculionidae) is one of the most destructive pests in palms in the world. In the Mediterranean Basin it is particularly damaging for Phoenix canariensis Hort. ex Chabaud. Different control methods have been applied within an integrated pest management (IPM) strategy (Gliblin-Davis et al., 2013) including synthetic insecticides, insect traps, plant extracts and biological control (Ajlan, 2000; Di Ilio et al., 2018; El-Shafie et al., 2011; EPPO, 2008; Faleiro, 2006; Murphy and Briscoe, 1999; Nassar and Abdullah, 2001; Oehlschlager, 1993; Wattanpongsiri, 1966). Until now no effective and economic method has been adopted for the total eradication of RPW and chemicals techniques are the most used. Due to different commercial products authorized by the national ministries of different countries, different results in the applications of the adopted molecules both in ornamental and date palms have been obtained. For this reason, a considerable interest towards solutions able to control the pest, with a minimum impact on the environment, has risen. The experience gained until now suggests that it is necessary to adopt preventive strategies that have primarily a protective character. If the palms are treated in the early stages of attack they can recover and their stability is not compromised. In this contest microwave heating is a particularly interesting tool. In recent years this technique has attracted great interest in the environmental engineering field. It is based on the transformation of the energy of these non-ionizing radiations, which cover both radiofrequency (RF) and microwaves (MW), into thermal energy when they interact with polar molecules (as water) and ions (Gabriel et al., 1996). Dielectric heating has been investigated for several applications designed for the volumetric heating of materials as rubber, wood, paper, agricultural products, for food processing and disinfestations (wheat, rice, fruit) (Lewandowski, 2001; Vincent et al., 2003; Wang and Tang, 2001; Wang et al., 2003) and it has been approved by the International Plant Protection Convention (IPPC) for the treatment of wood packaging materials, according to ISPM 15 Regulation of Wood Packing Material in International Trade of the FAO (FAO 2014, 2018; Henin et al., 2014). The idea of using MW against RPW is based on the fact that this radiation should be able either to induce a thermal increase in the pest, heating it to a lethal temperature without harming the plant tissues, or to affect the reproduction of survivors as reported in other papers (Hamid, 1968). In this work we present the feasibility of this approach and its application in Phoenix canariensis palms. The efficacy of the treatment has been proved in semi-field tests. RPW lethal temperatures can be easily reached in the external layers of the trunk. The surviving RPW (time) can be reduced as MW is able to affect their longevity and induce morphological alterations of the 
ovaries and testes in adult RPWs (both male and female). The measurements of thermal and electromagnetic parameters of the tissues involved (both insect and plant host) allowed to develop a thermal-electromagnetic model that is the base of a software validated both numerically and experimentally. The treatment can be optimized on the basis of the evaluation of the performance of the applicator and the developed tool, that can be easily adopted by not skilled operator. Once parameters (dimension of the palm, ambient temperature, wind conditions, penetration depth) are set, it is then possible to establish the power, modulation and duration of the treatment.

\section{Effectiveness of palm microwave sanitation in laboratory and semi-field tests}

The feasibility of microwave treatments of Phoenix canariensis to control RPW was reported by Massa et al. (2011). A preliminary semi-field test was performed on an infested plant $(30 \mathrm{~cm}$ diameter) treated with a truncated waveguide connected to a magnetron source $(2.45 \mathrm{GHz}, 1$ $\mathrm{kW}$ ) for $30 \mathrm{~min}$. During irradiation, thermal images were recorded with an infrared (IR) thermocamera and data showed that only the external region of the palm directly involved in the treatment reached high temperatures (about $70{ }^{\circ} \mathrm{C}$ ). Larvae and adults present in this section were found dead. These results highlighted a low thermal conductivity and were in agreement with that expected on the basis of laboratory tests on the electromagnetic characterization of both plant tissues (healthy and damaged by the pest) and insects (Massa et al., 2011; 2014). The data showed a microwave penetration depth of the order of a couple of centimeters at $2.45 \mathrm{GHz}$, due to the high water content in the plant tissues. In particular, by applying Ulaby model to our data (Ulaby and El-Rayes, 1987), the volume fraction of free water resulted higher than that of the bulk vegetation-bound water mixture in the damaged tissues. In the case of insects at $2.45 \mathrm{GHz}$, the loss factor on the surface of the adult resulted much lower than that of the larva (due to the reduced water content of the insect at this stage compared to that of the larva), and the penetration depth in the chamber was of many centimeters, thus allowing microwaves to reach the larva/adult depending on the stage of metamorphosis.

Microwave exposures carried out in the laboratory under controlled conditions confirmed these results. Larvae or adults were introduced into a short-circuited waveguide fed by a microwave source $(2.45 \mathrm{GHz})$, incident and reflected powers were measured by power meters and temperatures were monitored by an IR thermocamera
(Figure 1). With an incident power density of $5 \mathrm{~W} / \mathrm{cm}^{2}$, larvae suddenly reached lethal temperature, while adults longevity depended on the time exposure.

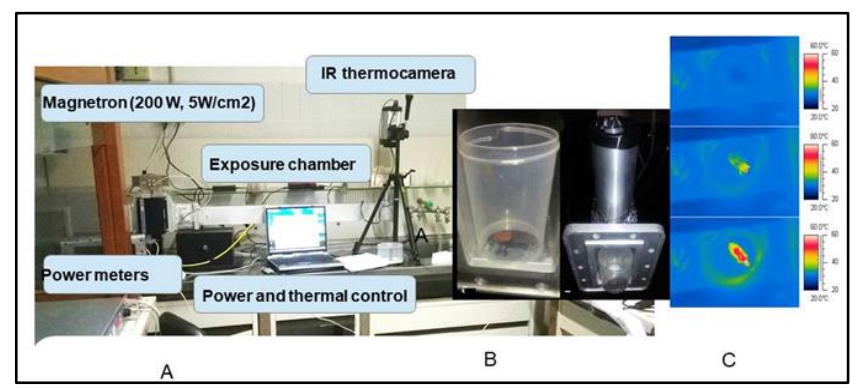

Figure 1. (A) Microwave exposure set up; (B) insect inserted into the waveguide; $(\mathrm{C})$ thermogram acquired during the exposure

Finally, an additional set of tests was performed on bigger Phoenix canariensis palms $(50 \mathrm{~cm}$ diameter) to estimate the efficacy of the treatment and the effect of the induced thermal stress. Eight out of thirteen palms were infested. Four infested palms and two healthy plants were microwave treated with a commercially available ring applicator (Ecopalm ring, Bielle s.r.l.). In Table 1 the exposure time and the number of alive and dead insects found in dissected palms ( $24 \mathrm{~h}$ after treatment) are reported.

As expected, an extremely high mortality was recorded in the case of insects blocked into cocoons. Adults were more affected than larvae (that were probably more inside the plant). The total effectiveness was between $60-90 \%$. Regarding the healthy microwave treated plants, they were observed for one month and compared with healthy and untreated palms. No effects of thermal stress were qualitatively observed.

\section{Impact of microwaves on RPWs reproductive organs}

Among the factors that influence the RPW's invasive potential there are the ability to complete several generations in a year even in the same tree and the high female fecundity. Females are usually attracted by palm volatiles and lay several eggs in dying or damaged parts of palms, although undamaged palms could also be attacked. After few days, eggs hatch into larvae which develop within the trunks of palms, frequently leading to the plant death (Faleiro, 2006; Giblin-Davis et al., 2013; Murphy and Briscoe, 1999; Wattanpongsiri, 1966).

Table 1. Effectiveness of the treatment. Alive or dead insects found after microwave treatment

\begin{tabular}{cccccccccccc}
\hline $\begin{array}{c}\text { Infested } \\
\text { Palm }\end{array}$ & $\begin{array}{c}\text { Treatment } \\
\text { time }\end{array}$ & $\begin{array}{c}\text { Living } \\
\text { Adults }\end{array}$ & $\begin{array}{c}\text { Dead } \\
\text { Adults }\end{array}$ & $\begin{array}{c}\text { Living } \\
\text { Larvae }\end{array}$ & $\begin{array}{c}\text { Dead } \\
\text { Larvae }\end{array}$ & $\begin{array}{c}\text { Living } \\
\text { Pupae }\end{array}$ & $\begin{array}{c}\text { Dead } \\
\text { Pupae }\end{array}$ & $\begin{array}{c}\text { \%Dead } \\
\text { Adults }\end{array}$ & $\begin{array}{c}\text { \%Dead } \\
\text { Larvae }\end{array}$ & $\begin{array}{c}\text { \%Dead \%Dead } \\
\text { Pupae }\end{array}$ & $\begin{array}{c}\text { Total } \\
\text { Total }\end{array}$ \\
\hline$\# 1$ & $30 \mathrm{~min}$ & 3 & 1 & 0 & 0 & 0 & 6 & 25 & - & 100 & 70 \\
$\# 2$ & $45 \mathrm{~min}$ & 2 & 25 & 3 & 2 & 0 & 6 & 92 & 40 & 100 & 87 \\
$\# 3$ & $45 \mathrm{~min}$ & 15 & 21 & 0 & 0 & 3 & 6 & 58 & - & 67 & 60 \\
$\# 4$ & $45 \mathrm{~min}$ & 5 & 10 & 0 & 1 & 0 & 1 & 67 & 100 & 100 & 71 \\
\hline
\end{tabular}


At present, different pest control methods have been adopted. Nevertheless, none has proven completely effective. Currently, a Sterile Insect Technique (SIT) (Dyck et al., 2005) is being developed to reduce fertility of the entire population of a specific pest in a particular area with minimal toxic effects (Llacer et al., 2013). Exposure to ionizing radiation is currently one of the methods for rendering insects reproductively sterile and it was proven effective even in RPW (Al- Ayedh, 2008; El Naggar et al., 2010; Paoli et al., 2014). Recently, microwaves heating has proven to be very useful in the environmental field. In a recent study, the morphologic and histological features of the male and female reproductive system of the RPW irradiated (Figure 1) at three different exposure time $(5 \mathrm{~s}, 15 \mathrm{~s}$, and 30 s) with microwaves $\left(2.45 \mathrm{GHz}, 5 \mathrm{~W} / \mathrm{cm}^{2}\right)$ were investigated (Martano et al., 2018). This study reported that the histological lesions in irradiated male and female RPWs were characterized by alterations of various severity levels ranging from degeneration to necrosis of germinal cells (Figure 2). The severity of the lesions increased with increase of irradiation time, showing severe alterations (necrosis) at $30 \mathrm{~s}$, in all female samples and in almost all males $(75 \%)$. Furthermore, the histological effects of radiation were similar to that observed in RPWs treated with insecticidal agents (El-Bokl et al., 2010), gamma rays (El Naggar et al., 2010; Paoli et al., 2014) and zinc sulfate (Al-Dhafar and Sharaby, 2012). Based on the results obtained, authors suggest that the impact of MWs on ovaries could lead to a progressive reduction of egg production and sterility of eggs, while on testis could induce loss of germinal cell, leading to a total lack of germ cells, with consequent arrest of spermatogenesis. These observations allow us to say that the MW could be an efficient way to reduce RPW population, because they could reduce or stop completely the reproductive ability of this insect.

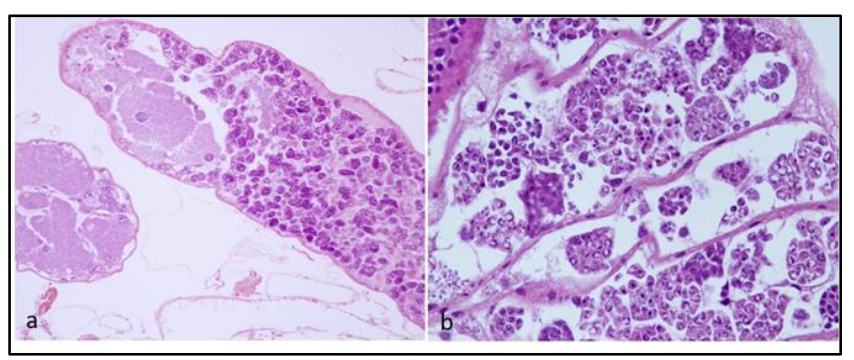

Figure 2. (a) Female RPW. Ovary. Vacuolar degeneration and necrosis of germinal cells were observed in $30 \mathrm{~s}$ irradiated samples (c; 20X) (Hematoxylin and Eosin). (b) Male RPW. Testis. In $30 \mathrm{~s}$ irradiated samples degenerative changes appeared in the precursors of spermatids and seminal epithelium (40X) (Hematoxylin and Eosin).

\section{Microwave optimization treatment}

One of the key problems in the microwave treatments of palms is their optimization, i.e. to estimate the microwave energy that must be radiated in order to reach the lethal temperature for the insect without damaging the palm. To reach this goal we proposed an electro-thermal model allowing the simulation of the thermal and electromagnetic processes involved in microwave heating. The model was validated both numerically and experimentally (Massa et al., 2017) and resulted in an in-house software named ThermPalm.

In this article a brief description of the steps followed to develop such a model is sketched. The interested reader can find more details in earlier reports (Massa et al., 2017), while in this paper we focus the attention on the practical indications obtained from the simulations, with special attention to the ThermPalm program results, that allow to identify the power, time and schedule necessary to obtain the lethal temperature at a certain depth, depending on the assumed palm infestation level.

We assumed a rapid substitution, during irradiation, of the evaporating water by other water drained by the plant (as Ulaby model suggested) and a negligible temperature dependence of thermal and electromagnetic parameters. In addition, we considered a cylindrically symmetric microwave illumination around the trunk of the palm and a longitudinal invariance. Consequently, all physical quantities in both thermal and electromagnetic models only depend on the radial coordinate and time and the analysis can be easily carried out by means of an FDTD (Finite Difference Time Domain) approach.

The thermal parameters of the palm were evaluated on an alive palm by measuring the temperature behavior during both microwave heating and cooling phases (Massa et al., 2017). To this end, a WR340 waveguide, fed by a magnetron source ( $1 \mathrm{~kW}$ incident power), was placed in front of the palm to be heated and two fiber optic probes, connected to the thermometer, were positioned at different depths inside the palm allowing accurate and non-perturbative temperature measurements in two points along the radius of the palm. The measurements of electromagnetic parameters, determined with the truncated coaxial technique (Migliore, 2000; Panariello et al., 2001; Romeo et al., 2011) and the mass density, are reported earlier (Massa et al., 2014). On the basis of thermal and electromagnetic parameters, taking into account the boundary conditions, and both natural and forced convection, a simple mono-dimensional electromagneticthermal code is able to predict, quite in real time, the thickness of the annular area in "living" palms wherein the RPW lethal dose (temperature and time) is reached without damaging the palm core that is the most relevant area for the life of the palm itself. The code has been employed with the commercial ring microwave applicator EcoPalm (patented by Bi.Elle s.r.l., (Figure 3) but could be used with different applicators. It consists in 12 magnetrons $(2.45 \mathrm{GHz}, 1 \mathrm{~kW}$ nominal power) arranged in a ring that can be closed around the palm in order to surround a section of the trunk. The magnetrons can be automatically controlled in order to optimize the treatment and can be turned on and off with a proper temporal cycle in order to increase the temperature inside the palm without reaching a too high temperature on the surface.

The user can set a number of parameters: environmental temperature, diameter of the palm, presence of wind, treatment depth and goal temperature. Other parameters are the power of the microwave applicator and the section of the palm to be treated (i.e. the height of the section of the palm), depending on the applicator. On the basis of these information the output is the duration of an on- 
off sequence of the magnetrons able to give the target temperature within the treatment depth set.

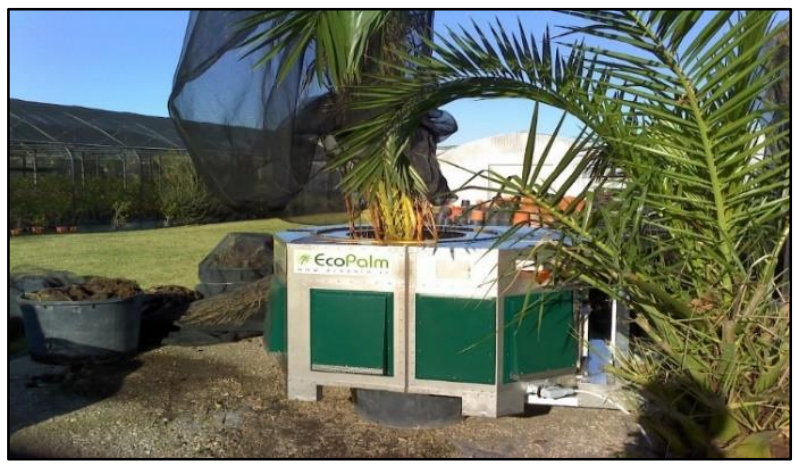

Figure 3. The EcoPalm ring applicator (patented by Bi.Elle s.r.1.).

As an example, we consider a $40 \mathrm{~cm}$ diameter palm, environmental temperature of $20{ }^{\circ} \mathrm{C}$ with no wind, $10 \mathrm{~cm}$ treatment depth and $55^{\circ} \mathrm{C}$ as goal temperature. The program identifies an optimal treatment with 7 on-off sequences lasting $7 \mathrm{~min}$ each.

In Figure 4, the heat distribution during the treatment is shown. The central figure (black curve) represents the turn on and turn off sequence. The temperature distribution (false colors) in a section of the palm and at different depths are shown in the higher and lower figure, respectively. At the beginning (time $\mathrm{t}=0$ ) the section of the palm has uniform temperature equal to the environment temperature. Then the magnetrons are turned on at the maximum power for 7 minutes. The increase of the temperature in the palm is clearly visible in the lower figure. Then the magnetrons are turned off. The outer part of the palm starts cooling, while the inner part increases the temperature due to the thermal diffusion process. After 7 minutes, the magnetrons are turned on again, causing a fast increase of the temperature on the outer part of the palm section. This helps the increase of the temperature in the inner part of the palm caused by the diffusion process. This turn-on turn-off process is repeated in order to meet the requirements set in the ThermPalm window.

The simulation clearly shows the physical processes at the basis of the increase of temperature of the palm. The microwave power is directly transferred to the palm tissue in the first $4-7 \mathrm{~cm}$, due to its high water content that strongly limits the penetration depth of microwaves inside the palm. In this area temperature increases very quickly since it is caused by direct microwave energy delivery. Instead, in the inner sections of the palm the thermal increase is due to the low heat conduction that is a much slower process. The onoff optimized sequence balances this two heating processes, allowing to reach the target temperature without dangerous thermal stress of the outer part of the trunk. It is worth noting that heat transfer due to convection on the surface of the palm is a parameter that plays an important role. Indeed, cooling of the surface can modify the temperature distribution inside the palm. In Figure 5, it is shown that the estimated temperature distribution inside the palm at the end of the onoff sequence with and without wind. A shift of the maximum temperature can be observed.

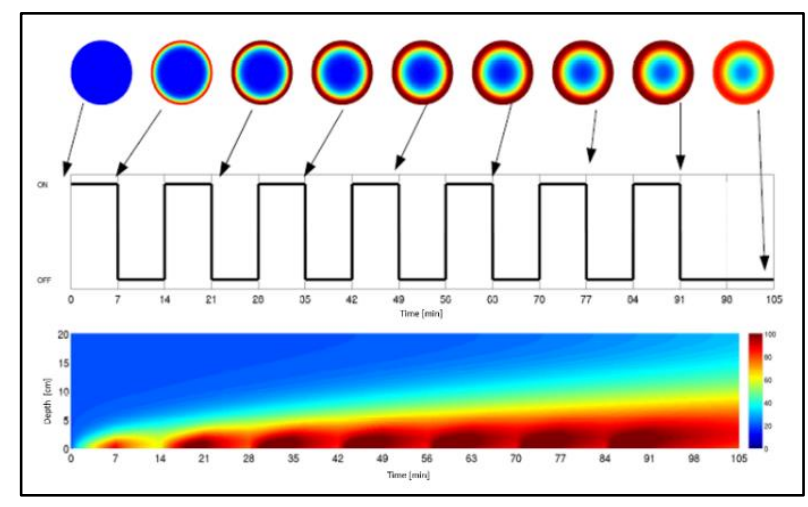

Figure 4. Temperature distribution in false colour in a section of the palm as function of time during the on-off cycles of the microwave applicator; the black curve represents the turn on-turn off sequence of the magnetron; in the lower figure the temperature at different depths of the palm (vertical axis of the figure) as function of time (horizontal axis of the figure) is shown; depth $=0$ is the surface of the palm, depth $=20 \mathrm{~cm}$ is the radius of the palm.

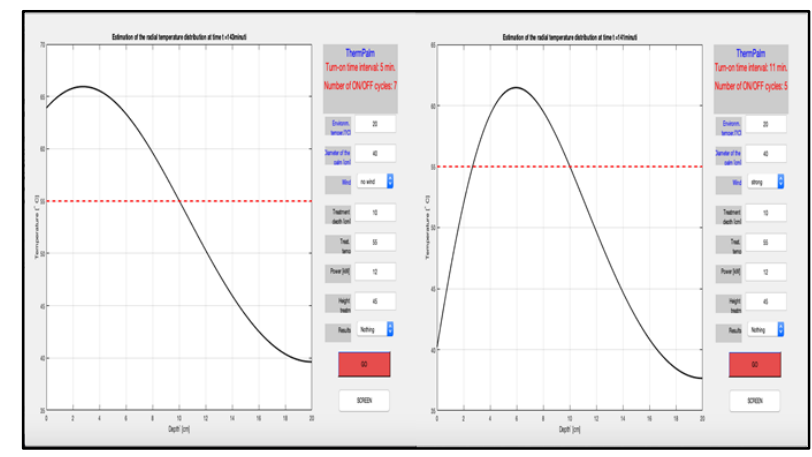

Figure 5. effect of wind on temperature distribution in the palm: left - no wind, right - strong wind.

\section{Conclusions}

MW heating of Phoenix canariensis palm resulted in an efficient, cheap and eco-compatible method to control RPW without affecting the plant, which could possibly be integrated in an IPM approach. Data showed that, with the adopted conditions, the microwave heating affects only the outer section of the palm, while the core remains quite cool. This is a relevant feature, since it matches two important requirements: the layers involved in the process are the regions where both the early stage and the pupal stage occur (it is worth noting that if the pest reaches the inner tissues, the palm irremediably dies and any treatment is useless); while keeping the core of the palm at lower temperature guarantees that microwaves do not affect the health of the plant. The process can be optimized by means of a suitable heating/cooling cycle, estimated by an in-house software implementing a simple electro-thermal model, validated both numerically and experimentally.

The knowledge and experience gathered in the case of Phoenix canariensis could be extended to other palm species attacked by one of the most destructive pests in the world. 


\section{Acknowledgements}

We would like to thank the Agriculture and Food commission of the Italian Senate for the interest in the research, and Campania Region, who supported this work in the framework of PSR Campania 2007-2013 Misura 124 MIPALM grant CUP N.B95C12000040004; finally, we would like to thank Bi.Elle Microwave Engineering, ConFlomer and Dr. Annamaria Greco for their technical support of the research.

\section{References}

Ajlan, A.M., M.S. Shawir, M.M. Abo-El-Saad, M.A. Rezk and K.S. Abdulsalam. 2000. Laboratory evaluation of certain insecticides against the red palm weevil Rhynchophorus ferrugineus (Oliver). Scientific Journal of King Faisal University, 1: 15-26.

Al-Ayedh, H. 2008. Evaluation of date palm cultivars for rearing the red date palm weevil, Rhynchophorus ferrugineus (Coleoptera: Curculionidae). Florida Entomologists, 9: 353-358.

https://doi.org/10.1653/00154040(2008)91[353:eodpcf $\rceil 2.0 . c 0 ; 2$

Al-Dhafar, Z.M. and A. Sharaby. 2012. Effect of Zinc Sulfate against the Red Palm Weevil Rhynchophorus ferrugineus with reference to their histological changes on the larval midgut and adult reproductive system. Journal of Agricultural Science and Technology A, 2: 888-900.

Di Ilio, V., N. Metwaly, F. Saccardo and E. Caprio. 2018. Adult and Egg Mortality of Rhynchophorus ferrugineus Oliver (Coleoptera: Curculionidae) Induced by Thiamethoxam and Clothianidin. IOSR Journal of Agriculture and Veterinary Science, 11: 5967. https://doi.org/10.9790/2380-1102016878

Dyck, V.A., J. Hendrichs and A.S. Robinson. 2005. Sterile Insect Technique: Principles and Practice in Area-wide Integrated Pest Management, Springer, Dordrecht, The Netherlands, $787 \mathrm{pp}$. https://doi.org/10.1007/1-4020-4051-2

El-Bokl, M.M., R.F.A. Baker, H.L. El-Gammal and M.Z. Mahmoud. 2010. Biological and histopathological effects of some insecticidal agents against red palm weevil, Rhynchophorus ferrugineus. Egyptian Academic Journal of Biological Sciences, 1: 7-22. https://doi.org/10.21608/eajbsd.2010.14151

El Naggar, S.E.M., H.F. Mohamed and E.A. Mahmoud. 2010. Studies on the morphology and histology of the ovary of red palm weevil female irradiated with gamma rays. Journal of Asia-Pacific Entomology,13: 9-16. https://doi.org/10.1016/j.aspen.2009.08.004

El-Shafie, H.A.F., J.R. Faleiro, A.A. Al-Abbad, L. Stoltman and A. Mafra-Neto. 2011. Bait-Free Attract and Kill Technology (Hook ${ }^{\mathrm{TM}}$ RPW) to Suppress Red Palm Weevil, Rhynchophorus ferrugineus (Coleoptera: Curculionidae) in Date Palm. Florida Entomologist, 94: 774-779. https://doi.org/10.1653/024.094.0407

EPPO. 2008 Rhynchophorus ferrugineus. EPPO Bulletin, 38: 55-59.

Faleiro, J.R. 2006. A review of the issues and management of the red palm weevil. Rhynchophorus ferrugineus (Coleoptera: Rhynchophoridae) in coconut and date palm during the last one hundred years. International Journal of Tropical Insect Science, 26: 135-154. https://doi.org/10.1079/IJT2006113

FAO. 2014. A quick guide on dielectric heating as a phytosanitary treatment for wood packaging material. Food and Agriculture Organization of the United Nations, International Plant Protection Convention (IPPC), Rome (ENG No. 04)

FAO. 2018. ISPM 15. Annex 1. Approved treatments associated with wood packaging material. Rome, IPPC, FAO. 
Gabriel, C., S. Gabriel and E. Corthout. 1996. The dielectric properties of biological tissues: I. Literature survey. Physics in Medicine and Biology, 41: 22312249. https://doi.org/10.1088/0031-9155/41/11/001

Giblin-Davis, R.M., J.R. Faleiro, J.A. Jacas, J.E. Peña and P.S.P.V. Vidyasagar. 2013. Biology and Management of the Red Palm Weevil, Rhynchophorus ferrugineus. Pages 1-34. In: Potential Invasive Pests of Agricultural Crop Species. J. E. Peña (ed.). CABI Wallingford, UK. https://doi.org/10.13140/2.1.1029.1202

Hamid, M.A. 1968. Control of grain insects by microwave power. Journal of Microwave Power, 3: 126-135. https://doi.org/10.1080/00222739.1968.11688679

Henin, J.M., M. Leyman, A. Bauduin, B. Jourez and J. He'bert. 2014. Phytosanitary treatment of European pallets by microwave: developing a program to ensure compliance with ISPM 15 and monitoring its efficacy on the house longhorn beetle (Hylotrupes bajulus L.). European Journal of Wood and Wood Products, 72: 623-633. https://doi.org/10.1007/s00107-014-0826-4

Lewandowski, J. 2001. Electromagnetic radiation for plant protection. Pages 111-161. In: Physical Control Methods in Plant Protection. C. Vincent, B. Panneton and F. Fleurat-Lessard (eds.). Springer, Berlin. https://doi.org/10.1007/978-3-662-04584-8

Llacer, E., C. Santiago-Álvarez and J.A. Jacas. 2013. Could sterile males be used to vector a microbiological control agent? The case of Rhynchophorus ferrugineus and Beauveria bassiana. Bulletin of Entomological Research, 103: 241-250. https://doi.org/10.1017/s0007485312000582

Martano, M., R. Massa, B. Restucci, K. Power, E. Caprio, R. Griffo, R. Ilsami and P. Maiolino. 2018. The use of microwaves in the control of the red date palm weevil Rhynchophorus ferrugineus (RPW) oliv. Coleoptera: Curculionidae: effects on ovaries and testis. Control of Red Palm Weevil, CIHEAM, Bari, 23/25-10-2018.

Massa, R., E. Caprio, M. De Santis., R. Griffo, M.D. Migliore, G. Panariello, D. Pinchera and P. Spigno. 2011. Microwave treatment for pest control: the case of Rhynchophorus ferrugineus in Phoenix canariensis. EPPO Bulletin 41.2: 128-135. https://doi.org/10.1111/j.1365-2338.2011.02447.x

Massa, R., M.D. Miglior, G. Panariello, D. Pinchera, F. Schettino, E. Caprio and R. Griffo. 2014 Wide Band Permittivity Measurements of Palm (Phoenix canariensis) and Rhynchophorus ferrugineus (Coleoptera Curculionidae) for RF Pest Control. Journal of Microwave Power and Electromagnetic Energy, 48: 158-169. https://doi.org/10.1080/08327823.2014.11689880

Massa, R., G. Panariello, D. Pinchera, F. Schettino, E. Caprio, R. Griffo and M.D. Migliore. 2017. Experimental and numerical evaluations on palm microwave heating for Red Palm Weevil pest control. Scientific Reports, 7: 45299. https://doi.org/10.1038/srep45299
Migliore, M.D. 2000. Partial self-calibration method for permittivity measurement using truncated coaxial cable. Electronics Letters, 36: 1275-1277.

Murphy, S.T. and B.R. Briscoe. 1999. The red palm weevil as an alien invasive: biology and the prospects for biological control as a component of IPM. Biocontrol News and Information, 20: $35 \mathrm{~N}-46 \mathrm{~N}$.

Nassar, M.M.I. and M.A. Abdullah. 2001. Evaluation of azadirachtin for control of the red palm weevil, Rhynchophorus ferrugineus (Oliver) (Coleoptera: Curculionidae). Journal of the Egyptian-German Society of Zoology, 36: 163-173.

Oehlschlager, A.C., C.M. Chinchilla, L.M. Gonzalez, L.F. Jiron, R. Mexzon and B. Morgan. 1993. Development of a Pheromone-based trap for the American Palm Weevil, Rhynchophorus palmarum (L.). Journal of Economic Entomology, 86: 1381-1392. https://doi.org/10.1093/jee/86.5.1381

Paoli, F., R. Dallai, M. Cristofaro, C.S. Arnone, V. Francardi and P.F. Roversi. 2014. Morphology of the male reproductive system, sperm ultrastructure and $\gamma$-irradiation of the red palm weevil Rhynchophorus ferrugineus Oliv. (Coleoptera: Dryophthoridae). Tissue Cell, 46: 274-285. https://doi.org/10.1016/i.tice.2014.06.003

Panariello, G., L. Verolino and G. Vitolo. 2001. Efficient and accurate full-wave analysis of the open-ended coaxial cable. IEEE Transactions on Microwave Theory and Techniques, 49: 1304-1309.

Romeo, S., L. Di Donato, O.M. Bucci, I. Catapano, L. Crocco, M.R. Scarfî and R. Massa. 2011. Dielectric characterization study of liquid-based materials for mimicking breast tissues. Microwave and Optical Technology Letters, 53, 1276-1280.

Ulaby, F.T. and M.A. El-rayes. 1987. Microwave Dielectric Spectrum of Vegetation - Part II: DualDispersion Model 2. IEEE Transactions on Geoscience and Remote Sensing. GE-25: 550-557. https://doi.org/10.1109/tgrs.1987.289833

Vincent, C., G. Hallman, B. Panneton and F. FleuratLessard. 2003. Management of agricultural insects with physical control methods. Annual Review of Entomology, 48: 261-281. https://doi.org/10.1146/annurev.ento.48.091801.1126 $\underline{39}$

Wang, S. and J. Tang. 2001. Radiofrequency and microwave alternative treatments for insect control in nuts: a review. Agricultural Engineering Journal, 10: $105-120$.

Wang, S., J. Tang, J.A. Johnson, E. Mitcham, J.D. Hansen, G. Hallman, S.R. Drake and Y. Wang. 2003. Dielectric properties of fruits and insect pests as related to radiofrequency and microwave treatments. Biosystems Engineering, 85: 201-212. https://doi.org/10.1016/S1537-5110(03)00042-4

Wattanpongsiri, A. 1966. A revision of the genera Rhynchophorus and Dynamis (Coleoptera: Curculionidae). Department of Agriculture Science Bulletin, Bangkok, 1: 1-328. 